\title{
O Marco da Carta Democrática Interamericana e Sua Interpretação no Processo de Impeachment da Presidente Dilma Rousseff: Repensando a Democracia
}

\section{Verônica Teixeira Marques}

Doutorado em Ciências Sociais pela Universidade Federal da Bahia (Ufba). Mestrado em Ciência Política pela Universidade Federal de Pernambuco (Ufpe). Coordenadora e professora do Programa de Pós-Graduação em Sociedade, Tecnologias e Políticas Públicas e da Graduação de Direito no Centro Universitário Tiradentes e do Mestrado em Direitos Humanos na Universidade Tiradentes. Pesquisadora do Instituto de Tecnologia e Pesquisa (ITP). http://lattes.cnpq.br/0156664290521652. http://orcid.org/0000-0001-6831-504X. veronica.marques@hotmail.com

\section{Vivianny Galvão}

Doutorado em Ciências Jurídicas pela Universidade Federal da Paraíba (UFPB). Professora do Programa de Pós-Graduação em Sociedade, Tecnologias e Políticas Públicas e da Graduação de Direito no Centro Universitário Tiradentes e de direito internacional. http://lattes.cnpq.br/3425520180308674. https://orcid.org/0000-0002-8433-4440 viviannygalvao@hotmail.com

\section{RESUMO}

Após repensar a categoria de democracia a partir dos teóricos clássicos e contemporâneos, como analisar a posição da CoIDH acerca da solicitação de opinião consultiva feita pelo secretário geral da Organização dos Estados Americanos a respeito do processo de impeachment da presidente Dilma Rousseff? O objetivo deste artigo foi, por meio de um estudo de caso, repensar os contornos da democracia. Verificou-se que a CoIDH negou o prosseguimento do pedido acerca da legitimidade do impeachment por unanimidade, ou seja, a Corte "opinou por não opinar". Levando-se em conta que o sistema interamericano considera a Carta manifesto em favor da democracia representativa nas Américas, propondo um conceito de democracia que transcende a ideia de democracia eleitoral, a decisão da Corte respeita as bases jurídicas da legislação internacional, mas é contraditória à da transcendência democrática, que vai além do voto. A metodologia utilizada foi qualitativa com método de estudo de caso.

Palavras-chave: Democracia. Impeachment. Sistema interamericano de direitos humanos.

THE FRAMEWORK OF THE INTER-AMERICAN DEMOCRATIC CHARTER AND ITS INTERPRETATION

IN THE PRESIDENT DILMA ROUSSEFF IMPEACHMENT PROCESS: RETHINKING DEMOCRACY

\section{ABSTRACT}

After rethinking democracy category from the theoretical classical and contemporary, to analyze the position of $\mathrm{CoIDH}$, on the request for an advisory opinion made by the Secretary General of the Organization of American States regarding the impeachment of President Dilma Rousseff? The purpose of this article, through a case study, was to rethink the characteristics of democracy. It was possible to verify that the ColDH denied the prosecution's request about the legitimacy of impeachment by unanimity, ie the Court "opined by no say." Taking into account the inter-American system considers the Charter as manifest in favor of representative democracy in the Americas proposed a concept of democracy that transcends the idea of electoral democracy, the decision of the Court concerning the legal basis of international law but is contradictory to the democratic transcendence that goes beyond the vote. The methodology was qualitative with case study method.

Keywords: Democracy. Impeachment. Inter-american system of human rights. SUMÁRIO

1 Introdução. 2 O compromisso democrático brasileiro. 3 Repensando, mais uma vez e de novo, a democracia. 4 Conclusões. 5 Referências. 


\section{INTRODUÇÃO}

No dia 23 de junho de 2016, a Corte Interamericana de Direitos Humanos (CoIDH) pronunciou-se acerca da solicitação de opinião consultiva feita pelo secretário geral da Organização dos Estados Americanos, senhor Luis Almagro Lemes, a respeito do processo de impeachment da presidente Dilma Rousseff. A CoIDH negou o prosseguimento do pedido por unanimidade com base nos argumentos que serão analisados mais adiante. Como pano de fundo dos argumentos do secretário geral e dos juízes interamericanos, está a Carta Democrática Interamericana adotada em 11 de setembro de 2001 na cidade de Lima.

O sistema interamericano considera a Carta um manifesto em favor da democracia representativa nas Américas, trazendo um conceito de democracia que transcende (termo usado na Carta) a ideia de democracia eleitoral. Esta transcendência decorre da inclusão do "governar democraticamente" por meio do respeito aos direitos humanos e liberdades fundamentais, do acesso ao poder, da separação e independência dos Poderes (artigo 3ㅇda Carta), etc. As manifestações de 2013, a crescente abstenção eleitoral, o afastamento da presidente eleita e a multiplicação de compromissos internacionais garantidores dos ideais democráticos, torna imperativo o repensar das categorias de democracia.

Este artigo realiza uma análise conceitual a partir dos dois documentos produzidos pelo sistema interamericano de direitos humanos no caso do processo de impeachment da presidente Dilma Rousseff. Embora a Carta Democrática Interamericana represente um marco, em qual categoria de democracia se encaixam os atos do secretário geral da OEA e da CoIDH no processo de impeachment da presidente Dilma Rousseff?

Diante disso, o principal objetivo aqui é repensar o conceito de democracia a partir de uma análise crítica dos argumentos trazidos tanto na solicitação de parecer feita pelo secretário geral da OEA quanto na decisão da CoIDH que nega o referido pedido.

A metodologia aplicada é qualitativa, de concepção construtivista social, apresentando um estudo de caso por meio de análise de texto e concentrando-se no conceito de democracia.

$\mathrm{O}$ artigo, inicialmente, analisa os dois documentos produzidos no âmbito da Corte Interamericana de Direitos Humanos, relativos ao caso do processo de impeachment da presidente Dilma Rousseff e, em seguida, os discute a partir de uma reflexão teórica sobre a democracia.

\section{COMPROMISSO DEMOCRÁTICO BRASILEIRO}

A possibilidade de afastamento do chefe de Estado e/ou chefe de governo das suas funções sob o argumento da responsabilização dos seus atos, significa, em tese, uma ampliação do exercício da democracia representativa. É claro que entre o que está posto na regulamentação e o modo como, de fato, a responsabilização ocorre, há um espaço muitas vezes obscuro e repleto de interesses escusos que em nada tem a ver com a representação do desejo popular. Entramos no fértil campo da significação dos conceitos que guiam, fundamentam e justificam o exercício do poder.

O processo de impeachment da presidente Dilma Rousseff gerou repercussões (e ainda gera) em âmbito nacional e internacional. Com relação a este último, vale ressaltar que desde a criação das Nações Unidas, em 1945, os termos "Estado", "democracia" e "direitos huma- 


\section{Democracia}

Humanos e

nos" são praticamente indissociáveis no discurso oficial estatal. ${ }^{1}$ Não é à toa que instituições internacionais tenham questionado o grau de consolidação da democracia brasileira no caso do processo de impeachment da Presidente Dilma Rousseff, com base na proteção dos direitos humanos.

No campo da atuação internacional, merece destaque a Organização dos Estados Americanos (OEA). A OEA é organização internacional em âmbito regional competente para proteger e garantir os direitos humanos e o pleno exercício da democracia representativa nos seus Estados-membros. Desde a nomeação do Secretário Geral, senhor Luis Almagro Lemes, ${ }^{2}$ a Organização tem assumido certo protagonismo no que se refere à observação e ao questionamento dos governos em torno do exercício democrático do poder. Em 10 de abril de 2016, o secretário geral da OEA, ao tratar dos desafios atuais da democracia na América Latina diante da Sociedade Interamericana de Imprensa, afirmou que:

La historia de la libertad de expresión y el pluralismo en América Latina no es lineal, es una historia de acelerador y freno. Todos nosotros, organismos internacionales como la OEA, la sociedad civil, los gobiernos, la gente que se expresa en las calles para protestar o a través de las redes sociales, periodistas que arriesgan su vida lamentablemente en el continente, los propietarios de medios, TODOS tenemos un papel que cumplir para asegurar que la libertad de expresión y el pluralismo predominen sobre intereses particulares. [...] Estamos frente a un hemisferio más diverso en el corte ideológico de sus gobiernos, algo que no debería afectar el compromiso regional con los valores de la democracia y los Derechos Humanos. En materia de Democracia y Derechos Humanos no hay variedad de grises. $Y$ eso vale para cualquier tipo de gobierno, independientemente del signo que sea. La democracia regional se ha logrado asentar desde el punto de vista formal en la gran mayoría de los países, queda mucho por hacer en la agenda de oportunidades económicas y sociales [...] (OEA, 2016b).

O secretário geral utiliza como marco da sua atuação, além dos tratados basilares da OEA, uma Assembleia Geral criada com a finalidade de consolidar e de dar sustento às democracias americanas: a Carta Democrática Interamericana (OEA, 2016a). Conforme a Assessoria de Assuntos Jurídicos da OEA, o principal requisito para invocar a CDI está na existência de atos que alterem a ordem constitucional e, consequentemente, afetem gravemente a ordem democrática do Estado-membro.

\footnotetext{
A investigação dos posicionamentos do Brasil nos discursos apresentados à Assembleia Geral das Nações Unidas, mostra que primazia dos direitos humanos pressupõe a construção de ambiência fundada em três pilares principais: desenvolvimento econômico, democracia e resolução pacífica dos conflitos. As posições brasileiras enfatizam a necessidade de que a sociedade internacional coopere com países menos desenvolvidos, pois somente com o desenvolvimento econômico seria possível atingir altos níveis de desenvolvimento social. O Brasil defende que a democracia deve ser vista como regime de governo no qual a titularidade do poder político reside nas mãos do povo, mas o discurso oficial brasileiro demonstrou que a concepção de democracia deve ir além do desejo da maioria, englobando os grupos considerados minoritários (MRE, 2016). Além disso, ainda na análise do discurso oficial do Brasil na Agnu, a adesão ao Estado de Direito é apresentada como justificativa das operações de paz multidimensionais instituídas nos territórios que estão em conflito armado. Dentre os princípios fundantes do Estado de Direito, o Brasil aponta para a igualdade perante a lei, a separação de Poderes, a governança democrática e a justiça social. Segundo os representantes do Brasil nas Nações Unidas, o Estado de Direito deve ser consistente com as normas internacionais de direitos humanos, uma vez que o respeito aos direitos humanos se revela o curso mais eficaz de estabelecer restrições ao poder governamental e de conter a "tirania da maioria" (MRE, 2016).

25 de maio de 2015. "[...] A partir de 26 de maio, como Secretário-Geral da OEA, os meus esforços serão focados em fazer da Organização um instrumento útil para os interesses de todos os Americanos, sejam eles do centro, do sul, do norte ou do Caribe [...]" (OEA, 2016c).
} 
Em meio a uma sucessão novelesca de eventos que culminaram no início do processo de impeachment da presidente Dilma Rousseff, a OEA foi contundente ao afirmar a falta de clareza nas motivações e nos procedimentos adotados pelo Congresso Nacional brasileiro. A insuficiência de informações fez com que, pela primeira vez no sistema interamericano, um secretário geral solicitasse parecer consultivo à Corte Interamericana de Direitos Humanos, invocando a CDI (artigo 20). ${ }^{3}$

O secretário geral defende a ideia de que em uma democracia representativa o juízo político deve respeitar o devido processo legal, e, além disso, deve observar o pleno respeito à separação dos Poderes e a presunção de inocência a fim de evitar violação aos direitos humanos e grave alteração dos princípios que regem todo o sistema democrático (ColDH, 2016). De acordo com o secretário geral, os pontos que poderiam afetar as garantias do devido processo legal no caso estudado são:

a. aquellas declaraciones formuladas al emitir su voto por quienes tienen que decidir la apertura de la causa y que suponen prejuzgar, adelantando opiniones de condena o de absolución o expresando fundamentos ajenos al asunto en consideración;

b. el explícito reconocimiento por parte de estas mismas personas de su sujeción a instrucciones, en desmedro de su imparcialidad requerida;

c. la invocación de causales comunes a varios funcionarios en contra exclusivamente de uno solo de ellos, y

d. la acusación por hechos que pudiesen haber sido ejecutados con anterioridad al período a ser considerado legalmente (CoIDH, 2016).

A CoIDH foi, então, invocada para se posicionar acerca da possibilidade de desrespeito à Carta e das consequências dos pontos suprassuscitados. Em suma, a Corte de São José deveria opinar se o processo de impeachment da presidente Dilma Rousseff tramita com observância às garantias do devido processo legal. A Corte foi unânime. Após elencar algumas considerações formais, a CoIDH diz compreender as preocupações do secretário geral da OEA mas que, neste caso concreto, existem limites genéricos ao exercício da opinião consultiva pelo Tribunal. ${ }^{4}$

\footnotetext{
3 (En 19 de mayo de 2016). El artículo 20 establece lo siguiente: "En caso de que en un Estado Miembro se produzca una alteración del orden constitucional que afecte gravemente su orden democrático, cualquier Estado Miembro o el Secretario General podrá solicitar la convocatoria inmediata del Consejo Permanente para realizar una apreciación colectiva de la situación y adoptar las decisiones que estime conveniente. El Consejo Permanente, según la situación, podrá disponer la realización de las gestiones diplomáticas necesarias, incluidos los buenos oficios, para promover la normalización de la institucionalidad democrática. Si las gestiones diplomáticas resultaren infructuosas o si la urgencia del caso lo aconsejar, el Consejo Permanente convocará de inmediato un período extraordinario de sesiones de la Asamblea General para que ésta adopte las decisiones que estime apropiadas, incluyendo gestiones diplomáticas, conforme la Carta de la Organización, el derecho internacional y las disposiciones de la presente Carta Democrática. Durante el proceso se realizarán las gestiones diplomáticas necesarias, incluidos los buenos oficios, para promover la normalización de la institucionalidad democrática" (CoIDH, 2016).

4 [...] 1. La Corte comprende la profunda preocupación del Secretario General, pero no puede menos que recordar su jurisprudencia en materia consultiva en lo atingente a la consulta de autos, a saber, que la petición de opinión consultiva: a) no debe encubrir un caso contencioso o pretender obtener prematuramente un pronunciamiento sobre un tema o asunto que podría eventualmente ser sometido a la Corte a través de un caso contencioso; b) no debe utilizarse como un mecanismo para obtener un pronunciamiento indirecto de un asunto en litigio o en controversia a nivel interno; c) no debe utilizarse como un instrumento de un debate político interno; d) no debe abarcar, en forma exclusiva, temas sobre los que la Corte ya se ha pronunciado en su jurisprudencia y e) no debe procurar la resolución de cuestiones de hecho, sino que busca desentrañar el sentido, propósito y razón de las normas internacionales sobre derechos humanos y, sobre todo, coadyuvar a los Estados miembros y a los órganos de la OEA para que cumplan de manera cabal y efectiva sus obligaciones internacionales [...] (ColDH, 2016).
} 


\section{Humanos}

Democracia

Os dois principais argumentos trazidos para negar o seguimento do pedido de opinião consultiva, delimitaram a atuação consultiva da ColDH. Inicialmente, a Corte sustentou que emitir um parecer sobre o processo de impeachment da presidente Dilma Rousseff poderia significar um pronunciamento prematuro acerca de uma questão que, em tese, pode ser submetida no futuro ao marco contencioso do Tribunal. Ademais, a Corte considera que a resposta à consulta poderia implicar em pronunciamento a respeito de assunto não resolvido em âmbito interno e isto desvirtuaria sua função consultiva (artigo 64.1 da Convenção Americana). Por fim, o Tribunal ressaltou que secretário pode exercer as funções reconhecidas pelo artigo 20 da Carta Democrática Interamericana discricionariamente, conforme sua própria avaliação (ColDH, 2016).

Diante de todos estes argumentos, vale destacar que, mesmo negando a continuação do pedido de parecer, a Corte "opina por não opinar". Ainda que o secretário defenda a observância de critérios jurídicos no processo político de autoridade nacional, a Corte optou por não se pronunciar juridicamente, mas reforçou a atuação política do secretário geral da OEA. O Brasil participa do sistema interamericano de direitos humanos desde sua criação e é signatário dos acordos mais importantes (Pacto de Bogotá, Tiar, Pacto de São José da Costa Rica). Diante do caso do processo de impeachment da presidente Dilma Rousseff, entretanto, os órgãos do sistema interamericano, um de essência política (secretário geral da OEA) e o outro de essência jurisprudencial (CoIDH), não parecem ter compreensões distintas acerca dos aspectos do exercício da democracia representativa. Vale ressaltar que são estas compreensões que pautam suas ações ou limitam o exercício de suas competências.

Torna-se imprescindível, portanto, repensar as categorias de democracia a fim de lançar um olhar mais crítico sobre a atuação dos agentes políticos e das instituições nacionais e, com destaque, neste artigo, internacionais.

\section{REPENSANDO, MAIS UMA VEZ E DE NOVO, A DEMOCRACIA}

Descobrir os mecanismos necessários para tornar a democracia um valor em si mesmo e não apenas um conjunto de regras de mediação do jogo político, é uma tarefa de grandes proporções. As discussões e análises sobre o tema têm-se encaminhado na perspectiva de explicar a democracia dentro de concepções teóricas preestabelecidas, pouco acrescentando à noção do senso comum. Dessa feita, o "natural" desencanto com a democracia e suas consequências precisam ser observados por meio de novas perspectivas teóricas.

$O$ advento da democracia liberal como proposta humana para administrar a permanente tensão estabelecida entre as muitas e distintas forças sociais, é o cerne da discussão moderna sobre a política. Pouquíssimas situações históricas, no entanto, expressaram tão claramente suas contradições como as que estão sendo vividas nessas décadas de passagem entre os séculos 20 e 21 . Também foram raros os teóricos que tornaram evidente a maneira como as crises sociais econômicas e políticas afetam, de forma indiscriminada, sociedades e Estados. Apesar disso, o contexto atual pode ser considerado um dos poucos momentos em que o debate sobre os problemas e desigualdades sociais é tão explícito. A exemplo da Revolução Francesa de 1789, que colocou em evidência a discussão sobre "direitos do homem e do cidadão" em defesa da liberdade e da igualdade, hoje cada vez mais a questão é retomada (MERQUIOR, 1991). 
Assim, o enfoque de uma "nova ótica democrática" anuncia a redefinição do significado de cidadania, de maneira que inclua as "minorias". Enfim, a fome, a violência e a exclusão, não são o único legado do século 20 e herança do século 21 , pois, além de produzir tecnológica e cientificamente a favor da sociedade, germinaram movimentos sociais, ampliadores da cidadania.

A ingerência dos setores organizados da sociedade civil brasileira nas discussões sobre os problemas do país, é indiscutível, mormente seus altos e baixos na pauta das questões políticas. Teoricamente a participação desses grupos passou a ser identificada por intermédio de análises sobre a atuação sociopolítica dos denominados "novos movimentos sociais" aclamados nas décadas de 70 e $80^{5}$ que, por sua vez, concomitantemente geravam a noção de "novas democracias". Essas, por sua vez, seriam "... aquelas cujas construções ocorrem em meio às condições políticas de uma transição na qual foi possível a completa eliminação de um passado autoritário" (WEFFORT, 1992, p. 85), ou seja, atreladas a um instante de transição de regimes autoritários para uma redemocratização, mas que não desembocaram, necessariamente, numa democracia "consolidada". As reivindicações e os debates gestados por esses movimentos, tanto no Brasil quanto em outras nações latino-americanas, evidenciaram o conteúdo dos problemas desses países.

Neste sentido, é preciso indicar que, sem desconsiderar a universalidade deste fenômeno no fim do século 20, geralmente são as realidades nacionais que estabelecem o parâmetro de atuação desses grupos. Enquanto na Europa e nos Estados Unidos o esfacelamento do "estado do bem-estar" trazia problemas antes não resenhados (miséria, desemprego, déficit previdenciário), no Brasil e na América Latina os reflexos dos regimes ditatoriais, consoantes às carências sociais crônicas, explicitaram contradições internas.

Nesse contexto, novas dinâmicas políticas, novos discursos e novas formas de conflitos e identidades foram inaugurados, o que revelou o potencial político e inovador sobre a sociedade e a cultura. Delimita-se, então, uma nova visão sobre a democracia que havia tornado possível a incorporação de novas questões ao debate político contemporâneo. A noção de democracia liberal como proposta humana para administrar a diversidade de interesses e equilibrar a tensão entre distintas forças sociais, traz em si duas questões complementares: a de encantamento pela possibilidade de adequação de interesses múltiplos e diferenciados e a responsabilidade de desenvolver essas possibilidades de maneira viável.

Na realidade, o que torna a democracia um sistema político praticamente hegemônico em todo o mundo é sua simbiose com o sistema capitalista. Essa relação de interesses entre um sistema econômico e uma forma de organização política, caracteriza-se por uma base nos princípios de liberdade individual que propicia um apoio mútuo, o que possibilitou esse alcance mundial. Desta feita, falar em democracia na atualidade é ter em mente o indissociável modelo econômico que lhe é inerente.

Nos países em que essa correlação se desenvolveu, o sistema político democrático é algo natural na realidade social, o que não ocorre no Brasil e na América Latina. As condições históricas nacionais que propiciaram o capitalismo, não forneceram qualquer base social, eco- 
nômica ou ideológica na perspectiva liberal (DREYFUS, 1980). Para o Brasil e outros países "ditos" periféricos, no entanto, a democracia liberal não é natural, uma vez que as "liberdades formais" não estão em conformidade com as "liberdades reais" (COMPARATO, 1989).

Assim, é importante discutir minimamente o conceito polissêmico de democracia e, nesse sentido, é preciso elucidar que a mesma não se restringe à existência de determinadas regras, procedimentos e rituais, mas à qualidade a ela inerente; uma discussão que se estende desde Aristóteles, quando o mesmo classifica a constituição da sociedade não apenas numa mera alusão às leis que, porventura, regulem a interação entre os indivíduos numa comunidade, mas, sobremodo, como as mesmas leis são compreendidas, veladas e reguladas, tendo como alicerce os vínculos entre os mesmos indivíduos de sociedade, de forma que esta se reproduza e se perpetue não apenas biologicamente. ${ }^{6}$

Aristóteles, porém, não era um democrata, nem um entusiasta da democracia. Sua ideia de constituição como algo inerente aos indivíduos que manteriam a própria sociedade, e não apenas a uma ideia normativa, estaria no centro do debate político que, durante a evolução da Civilização Ocidental, tornar-se-ia o principal foco de atenção em que teóricos políticos, de Maquiavel a Marx, passando obviamente por Weber, concentrariam suas atenções: a divisão do poder; ${ }^{7}$ divisão esta que estaria, primeiramente, representada na mera representatividade individual por meio do voto, mas que, paulatinamente, se deslocaria para outros eixos, como o da consideração das vontades individuais e coletivas dos governados pelos governantes.

\footnotetext{
Cf. ARISTÓTELES. A política. 2. ed. São Paulo: Martins Fontes, 1998.

Maquiavel (1997) tem o mérito de distinguir e diferenciar o Estado do governo, dando início à despersonalização do poder. Com o advento do contratualismo, especialmente com Hobbes (1997) e Locke (1998), a ideia do poder político estar relacionado ao consenso social estabelecido por um contrato entre os indivíduos, faz estremecer as fundações do absolutismo monárquico, muito embora as perspectivas destes dois autores divirjam quanto à perenidade e a transitoriedade dos governos estabelecidos pelo contrato. Montesquieu (1996), ao formular sua teoria da divisão entre os poderes, também não está preocupado apenas com os elementos procedurais e formais, mas com a perpetuidade de uma sociedade alavancada na perspectiva de uma ação política consciente dos cidadãos membros de uma comunidade. Com Rousseau (1997), o contratualismo concentra-se mais em seus desdobramentos factuais, quando o autor se preocupa em demonstrar que, por mais legítimo que possa ser a origem da sociedade num contrato, o mesmo não pode se manter sem uma divisão dos poderes entre os indivíduos membros da sociedade, e não apenas em instituições que os representem. Em Tocqueville (1977), a política passa a ser considerada a partir de um elemento crível: a democracia. Não apenas em conceito, mas em aplicabilidade num mundo real em que a produção industrial e a livre-iniciativa estarão juntas na edificação de um ideal democrático que não se limitaria apenas ao aspecto representativo individualista, mas, principalmente, tendo a democracia como forma de sociedade mais que uma mera forma de governo. Hegel (1990) introduzirá, de forma mais específica, a divisão entre a sociedade civil e o Estado, representando, respectivamente, os interesses de ordem privada e os de ordem pública. Stuart Mill (1981), por sua vez, demonstra que, tanto para a sobrevivência dos Estados quanto para a perpetuação da sociedade, os valores da democracia não poderiam estar restritos a um setor, ou setores da sociedade. O voto, o sufrágio, seria um mecanismo eficaz de consciência cívica e representação social próprios a uma elevação econômica, política e social da própria sociedade. Marx (1978) será um crítico contundente de todas estas abordagens, uma vez que sua crítica se concentrava no exclusivismo da ideia de democracia burguesa assentada na exploração econômica de grande parte da sociedade. Mesmo em sua crítica, entretanto, observa-se a preocupação com a justiça social e a mobilização da sociedade por meio de movimentos sociais que, dinamicamente, seriam capazes de pressionar os governos quanto a uma melhoria não apenas de condições de trabalho, mas de uma melhor distribuição do próprio poder. Weber (1993) será o grande sintetizador deste périplo, em que a noção e a ideia do poder é uma constante. Para o mesmo, o mundo da passagem do século 19 para o 20 havia colocado novas diretrizes de costumes e pensamentos que, ante as tradições, ditariam os padrões de avanço e retrocesso das sociedades em relação aos processos de ordem política, social, econômica e cultural. O homem estaria inserto num redemoinho em que a razão e a emoção ditariam os patamares dos conflitos endógenos e exógenos às sociedades e aos Estados.
} 
Pensar a democracia nesses termos é entender que seus procedimentos são um meio e, não necessariamente, um fim. Isso sugere que enfatizar apenas as formalidades pode incorrer em reducionismos, o que excluiria uma participação política mais efetiva. Dessa forma, o objetivo real da democracia pretenderia o alcance do bem comum e de uma maior igualdade econômica e social. Isto, no entanto, estaria reservado a todas as sociedades ou a algumas?

Se o debate clássico deteve-se nas condições de constituição, organização e distribuição do poder, mais recentemente pareceu estar relacionado a um certo determinismo histórico-economicista, em que a democracia seria sinônimo de modernização. Em suma, quanto mais industrializada fosse uma sociedade, maior as chances de ser democrática, especialmente se tal industrialização tivesse sido iniciada no século 19. Este é o foco de análise de autores como Lipset (1967) e Moore Jr. (1983).

Lipset afirma que há três condições para que a democracia se afirme numa sociedade. A primeira delas é que deve haver um sistema de valores que permita o pacífico jogo do poder. A segunda é a de que as alternâncias neste mesmo poder conduzam a sociedade a um patamar de normalidade assentada no respeito às regras do jogo. A terceira é a de que devem existir condições para que as regras do jogo sejam respeitadas a partir da influência popular no poder, e não a partir do concentracionismo burocrático, que afastaria das decisões o grosso da sociedade (LIPSET, 1967, p. 45).

Lipset, no entanto, afirma que isto somente é possível em sociedades economicamente avançadas, pois “... a democracia está relacionada com a situação do desenvolvimento econômico. Quanto mais próspera for uma nação, tanto maiores são as probabilidades de que ela sustenha a democracia" (Ibidem, p. 49). Enfim, as democracias estariam diretamente relacionadas às nações mais prósperas, enquanto às demais restaria apenas a necessidade de se desvencilhar dos grilhões da tradição.

Moore Jr. (1983) também aproxima-se da perspectiva de Lipset, sendo, contudo, mais determinista quanto às condições de um desenvolvimento propício à democracia. Para o mesmo, o problema não estaria necessariamente atrelado ao âmbito econômico, mas à capacidade de uma determinada parcela da sociedade em substituir os entraves ao desenvolvimento econômico, político e social da mesma, substituindo uma determinada classe que concentra os destinos da própria sociedade. Assim sendo, a modernização não seria apenas econômica, muito embora não deixe de estar presente em suas reflexões. Para Moore Jr., a democracia, ou a possibilidade desta, estaria representada no desenvolvimento de um grupo na sociedade, com uma base econômica sólida e independente, que pudesse atacar os empecilhos ao desencadeamento de uma sociedade ao mesmo tempo capitalista e democrática. Isto levaria a três caminhos: o capitalismo; o fascismo e o comunismo; cada um destes representando a maior ou a menor capacidade, dos grupos sociais independentes, de se desvencilhar das amarras do tradicionalismo e da influência das classes sociais mais tradicionalistas.

Ambos os autores tentam aplicar os conceitos weberianos de "tradicionalismo" e "modernização". Ao contrário do pensador alemão, contudo, não procuram fornecer elementos capazes de elucidar as razões para que umas nações se tornassem democráticas e outras não. A grande lacuna gerada por estas análises é a de que os indivíduos não são tomados como agentes transformadores de uma realidade na qual estão inseridos, mas apenas espectadores de seus próprios destinos. A democracia é, simplesmente, um adendo de uma certa transfor- 


\section{Democracia}

Humanos e

mação teleológica, transformando-se num instrumental capaz de se adaptar, a partir de um núcleo comum, às mais díspares circunstâncias. Como, então, diagnosticar o que viria a ser democracia?

De acordo com Bobbio (1997), a democracia nada mais seria que "... um conjunto de regras que estabelecem quem está autorizado a tomar as decisões coletivas e com que procedimentos". Fica implícita aqui a necessidade de operacionalizar o conceito ao vincular uma determinada forma de adquirir o poder e as tomadas de decisão políticas. Sobre essas considerações, pode-se afirmar que o conceito de democracia estaria intrinsecamente ligado a uma opção social (TOURAINE, 1996) e, nesse sentido, vários teóricos apontam distintos caminhos a respeito do conceito ora discutido.

Schumpeter (1961) caracteriza a democracia como um método que desconsidera questões adjetivas ou de conteúdo. Outro fator que não pode ser desconsiderado no debate acerca das democracias modernas é aquilo que Hans Kelsen (1993) assevera em relação aos partidos políticos. Para o mesmo, a democracia é essencialmente de partidos políticos, porquanto que, sem os mesmos, não haveria como representar os interesses conflitantes dos indivíduos, grupos e setores da sociedade. ${ }^{8}$

A grande síntese de toda esta discussão, porém, pode ser dada por Robert Dahl (1997), que sintetiza a possibilidade da democracia numa perspectiva aproximativa, quando a capacidade dos indivíduos de formularem, exprimirem e terem suas preferências levadas em consideração pelo governo determinam um sistema mais, ou menos, competitivo.

De acordo com Dahl, entretanto, a democracia seria um ideal a ser alcançado. O que se poderia afirmar é que há sociedades em que a competição política e o direito à participação dos indivíduos se dão em melhores e maiores condições que outras, posto que uma das características da democracia para este autor é "... a contínua responsividade do governo às preferências de seus cidadãos, considerados como politicamente iguais" (Ibidem, p. 25). ${ }^{9}$ O que Dahl denomina de responsividade, é justamente a interação, de bases institucionais, entre o governo e a sociedade civil, em que as organizações subnacionais (associações, sindicatos, movimentos sociais, etc.) teriam um papel não apenas de representação, mas de pressão e persuasão junto aos Poderes constituídos.

Neste sentido, os movimentos sociais, os partidos políticos, as instituições e outros elementos aglutinadores da vontade coletiva, passariam a representar, na sociedade contemporânea, meios de intervenção e participação dos indivíduos nos destinos da sociedade em que está inserido. ${ }^{10}$ De fato, isto pode até mesmo provocar um salto qualitativo entre os partícipes

\footnotetext{
8 No Brasil, essa perspectiva fica um tanto quanto comprometida, posto que as relações políticas com os partidos são altamente frouxas e desestruturadas. A representatividade política se estabelece na figura dos sujeitos e não na dos partidos, isso para não entrarmos na discussão da fidelidade partidária. Os representantes da sociedade brasileira não são os partidos e sim os indivíduos. Algumas ideias a esse respeito são indicadas por Baquero e Castro (1996).

9 Para Robert Dahl, sendo a democracia um ideal a ser alcançado, nenhuma sociedade no mundo havia alcançado tal patamar. Neste sentido, denomina de Poliarquia as sociedades mais próximas deste ideal. Cf. DAHL, Robert. Poliarquia. Participação e oposição. São Paulo: Edusp, 1997.

${ }^{10}$ A questão acerca do indivíduo $x$ grupo (sociedade) é bastante polêmica nas Ciências Sociais. Neste trabalho, a noção em voga aproxima-se das considerações de Lasswell e Kaplan, quando sustentam que “... os conceitos de um ato e da ação de uma única pessoa não devem ser interpretados como uma minimização da importância dos grupos em relação a dos indivíduos no processo político. A significação deste ponto de partida é puramente lógica: o ato do grupo é interpretado como um conjunto de atos individuais" (KAPLAN; LASSWELL, 1998, p. 31, grifo nosso).
} 
do processo político, sejam eles "representantes" ou "representados", governantes ou governados. Isto se deve ao fato de que, com uma maior participação política, o "primitivismo" e o "negativismo democrático", como os denomina Sartori (1996), tendem a desaparecer, e a política passa a ser vista como um exercício normal de experiência particular e coletiva.

Todas essas indicações sobre a democracia não dão conta de sua complexidade e, por mais distintas que sejam as interpretações, o que importa frisar é a averiguação de condições que propiciem uma maior estabilidade política do processo de democratização.

Por "estabilidade política" entende-se a capacidade que determinado sistema possui de se perpetuar. Voltando ao conceito de Bobbio (1997), se a democracia é fundamentalmente um sistema institucional para tomadas de decisão, poderia cair no reducionismo, crendo que é o fortalecimento das instituições que delimita a estabilidade democrática.

Outro aspecto significativo nessa discussão é o liberalismo. Em Bobbio (1986, 1987, 2002b) também é possível encontrar uma síntese reflexiva das vantagens e limites do liberalismo e da democracia, bem como a proposição e a discussão, antes da teorização sociológica de Giddens $(1996,2001)$ da terceira via. ${ }^{11}$

Sendo um neocontratualista, a terceira via, segundo Bobbio, representa a possibilidade de se assegurar, concomitantemente, os princípios liberais de autonomia e liberdade com os fundamentos igualitários da democracia, que poderia ser conceituada como liberalismo social, sendo, antes de tudo, não a negação e a superação dos opostos da díade esquerda e direita, mas o reconhecimento das diferenças ideológicas como fundamental para o aprimoramento do jogo democrático. Bobbio $(2000,2002 b, 2002 c)$ vislumbra, na retração do direito público, a decadência do processo político; daí sua crítica ao socialismo e ao comunismo, que viam, no Estado de Direito, a concepção marxista de Estado Burguês, bem como ao liberalismo, que defende, primordialmente, o princípio das garantias individuais.

Um outro neocontratualista - John Rawls $(2000,2003)$ - discute que, mais que democracia e participação, é preciso haver verdadeira igualdade de condição precípua de justiça, sem a qual não haverá espaço para o exercício pleno da liberdade. Para tanto, Rawls (1981) coloca dois meios necessários para que a justiça social se torne exequível: a cada indivíduo deve caber o máximo de liberdade compatível para com outro indivíduo; e a desigualdade social somente deve ser permitida para beneficiar os menos favorecidos.

Com esta fórmula, Rawls (2002) defende a concepção de que o mérito e a capacidade individual, desde que asseguradas condições para tanto, devem regular as relações entre os indivíduos. Isto seria afiançado pelo que o autor denomina as cinco categorias de bens primários: as liberdades básicas (consciência e crença); a liberdade de movimento (defender,

\footnotetext{
${ }^{11}$ A discussão sobre a terceira via em Bobbio deve ser mais bem esclarecida. Primeiramente, Bobbio (1987) reconhece o deslocamento das decisões centro-periferia tendo os comitês de bairro como exemplo. Ao mesmo tempo, critica os partidos de esquerda por não despersonalizar a relação representado-representante, uma vez que ainda setorizavam esta relação em base ideológica, e não comunitária e social. Por outro lado, Bobbio (1994a) argumenta que não há terceira via. Este argumento, no entanto, é desenvolvido como uma crítica à esquerda italiana (socialistas e comunistas), que buscava uma alternativa à democracia burguesa e à socialdemocracia, bem como uma censura à ausência de uma maior exatidão nas propostas de outros partidos. Bobbio relembra que até os fascistas se colocavam como terceira via. Assim sendo, a terceira via em Bobbio nada mais é que a manutenção da democracia como regra do jogo, o aperfeiçoamento da participação popular para além da democracia representativa e o avanço das concepções de governo baseadas na busca pela justiça social.
} 


\section{Humanos e}

Democracia

sustentar e modificar ideias e concepções); os poderes e as prerrogativas (autonomia do eu); a renda e a riqueza; e as bases sociais do respeito próprio. Assim, a democracia estaria garantida em bases racionais de um conceito empírico de justiça.

Outra reflexão acerca dos parâmetros democráticos na sociedade moderna localiza-se na obra de Robert Dahl $(1997,2001)$, particularmente sua Poliarquia. Analisando as sociedades existentes, das mais democráticas às mais autoritárias, Dahl sustenta a ideia de que o ideal democrático é pouco representado nestas sociedades. Assim sendo, as mais próximas dos parâmetros democráticos são consideradas poliarquias, dado que o avanço em direção ao ideal democrático se daria pela progressiva ampliação da competição e da participação política dos indivíduos na sociedade. Dahl (1997) considera que em sociedades poliárquicas deve haver três requisitos para que estes dois eixos (competição e participação) possam ser executados: a formulação de preferências; a expressão de preferências; e a consideração das preferências pelo governo.

Consequentemente, a mera participação em um processo eleitoral não garante que uma sociedade seja democrática. Para tanto, há a necessidade de liberalização (contestação pública das decisões governamentais) e inclusividade (participação nas decisões políticas na esfera pública). O ponto ótimo desta relação cartesiana é que quanto maior o índice de liberalização e inclusão maior é a possibilidade de aproximação de um ideal democrático.

\section{CONCLUSÕES}

Após repensar a categoria de democracia a partir dos teóricos clássicos e contemporâneos, como analisar a posição da ColDH acerca da solicitação de opinião consultiva feita pelo secretário geral da Organização dos Estados Americanos, a respeito do processo de impeachment da presidente Dilma Rousseff? A ColDH negou o prosseguimento do pedido por unanimidade, ou seja, a Corte "opinou por não opinar".

Levando-se em consideração que o sistema interamericano considera a Carta como manifesto em favor da democracia representativa nas Américas, propondo um conceito de democracia que transcende a ideia de democracia eleitoral, a decisão da Corte respeita as bases jurídicas da legislação internacional, mas é contraditória à da transcendência democrática que vai além do voto.

Tendo em vista que essa transcendência se delineia pela prerrogativa que vai além do "governar democraticamente", o que é possível quando se busca o respeito aos direitos humanos e liberdades fundamentais, o respeito do acesso ao poder, da separação e independência dos poderes, os fenômenos que antecederam o processo de impeachment, como as manifestações de 2013, a crescente abstenção eleitoral identificada nas eleições dos últimos anos e, em especial, em 2016, o afastamento da presidente eleita e a multiplicação de compromissos internacionais garantidores dos ideais democráticos, torna-se imperativo o repensar das categorias de democracia.

Partindo-se do princípio de que uma democracia se sustenta em um sistema de valores que permita o pacífico jogo do poder, não se pode deixar de levar em consideração, também, que esse jogo se sustenta na capacidade que a política tem de proporcionar alternâncias neste mesmo poder, única condição para conduzir a sociedade a um patamar de normalidade assentada no respeito às regras do jogo. 
O que infere da decisão da ColDH se baseia em preceitos jurídicos e políticos, mas não leva em conta as condições para que as regras do jogo sejam respeitadas a partir da influência popular no poder, e não a partir do concentracionismo burocrático, que afastou das decisões o grosso da sociedade.

Levando em consideração as análises de Lipset e Moore Jr., pode-se indicar a inabilidade de uma determinada parcela da sociedade em substituir os entraves ao desenvolvimento econômico, político e social da mesma, substituindo uma determinada classe que concentra os destinos da própria sociedade.

Não se pode deixar de salientar que os argumentos usados pela ColDH para decidir não opinar sobre o impeachment, sustentam-se porque a Corte não pode resolver conflitos internos dos países mas, sim, tem a função precípua de interpretar as normas internacionais e aplicabilidade dos direitos humanos.

\section{REFERÊNCIAS}

ARISTÓTELES. A política. 2. ed. São Paulo: Martins Fontes, 1998.

BAQUERO, M (org.). Cultura, política e democracia. Os desafios das sociedades contemporâneas. Porto Alegre: EDUFGRS, 1994.

BAQUERO, M.; CASTRO, H. C. de O. A erosão das bases democráticas: um estudo de cultura política. In: BAQUERO, M. (org.). Condicionantes da consolidação democrática: ética, mídia e cultura política. Porto Alegre: Ed. Universidade/UFRGS, 1996.

BOBBIO, Norberto. "Sociedade civil”. In: BOBBIO, N.; MATTEUCCI, N.; PASQUINO, G. Dicionário de política. 2. ed. Brasília: Editora UNB, 1986.

BOBBIO, Norberto. As ideologias e o poder em crise. Pluralismo, democracia, socialismo, comunismo, terceira via e terceira força. 3. ed. Brasília: Edunb, 1994a.

BOBBIO, Norberto. Liberalismo e democracia. 5. ed. São Paulo: Brasiliense, 1994b.

BOBBIO, Norberto. Diálogo em torno da República. Os grandes temas da política e da cidadania. Rio de Janeiro: Campus, 2002a.

BOBBIO, Norberto. Elogio da serenidade. E outros escritos morais. São Paulo: Unesp, 2002b.

BOBBIO, Norberto. O Futuro da Democracia. 8. ed. São Paulo: Paz e Terra, 2002c.

BOBBIO, Norberto. Qual socialismo? 3. ed. Rio de Janeiro: Paz e Terra, 1987.

BOBBIO, Norberto. Teoria geral da política. Rio de Janeiro: Campus, 2000.

BOBBIO, Norberto. Estado, Governo, Sociedade. 7. ed. Rio de Janeiro: Paz e Terra, 1986.

BOBBIO, Norberto. Os intelectuais e o poder: dúvidas e opções dos homens de cultura na sociedade contemporânea. Trad. Marco Aurélio Nogueira. São Paulo: Editora da Unesp, 1997.

COMPARATO, Fábio Konder. Para viver a democracia. São Paulo: Brasiliense, 1989.

COIDH. Corte Interamericana de Direitos Humanos. Rejection to the request of advisory opinions. Disponível em: http://www.corteidh.or.cr/cf/Jurisprudencia2/rechazo_solicitud_opiniones_consultivas.cfm?lang=en. Acesso em: 27 jul. 2016.

COMPARATO, Fábio Konder. Para viver a democracia. São Paulo: Brasiliense, 1989.

DAHL, R. Poliarquia. São Paulo: Edusp, 1997.

DAHL, R. Sobre a democracia. Brasília: Edunb, 2001.

DREYFUS, Hubert L. Michel Foucault, uma trajetória filosófica: para além do estruturalismo e da hermenêutica. Rio de Janeiro: Forense Universitária, 1995.

GIDDENS, A. A terceira via e seus críticos. Rio de Janeiro: Record, 2001.

GIDDENS, A. Para além da esquerda e da direita. São Paulo: Unesp, 1996.

HABERMAS, Jürgen. Direito e democracia: entre facticidade e validade. Rio de Janeiro: Tempo Brasileiro, 1997 . V. I. (Biblioteca tempo universitário, 101).

HABERMAS, Jürgen. Direito e democracia: entre facticidade e validade. Rio de Janeiro: Tempo Brasileiro, $1997 \mathrm{~b}$. V. II. (Biblioteca tempo universitário, 102). 


\section{Humanos e \\ Democracia}

HEGEL, G. W. F. Fenomenologia do espírito. 2. ed. Petrópolis: Vozes, 1993.

HEGEL, G. W. F. Princípios da Filosofia do Direito. Lisboa: Guimarães, 1990.

HOBBES, T. O Leviatã. São Paulo: Nova Cultural, 1997. (Coleção Os Pensadores).

KAPLAN, Abraham; LASSWELL, Harold. Poder e sociedade. 2. ed. Brasília: Edunb, 1998.

KELSEN, H. A democracia. São Paulo: Martins Fontes, 1993.

LAMOUNIER, Bolívar (org.). A ciência política nos anos 80. Brasília: Edunb, 1982.

LOCKE, J. Dois tratados sobre o governo. São Paulo: Martins Fontes, 1998.

LIPSET, S. M. O homem político. Rio de Janeiro: Zahar, 1967.

MAQUIAVEL, N. Comentários sobre a primeira década de Tito Lívio. 3. ed. Brasília: Edunb, 1994.

MARX, Karl. O 18 Brumário e Cartas a Kugelmann. 5. ed. Rio de Janeiro: Paz e Terra, 1978.

MERQUIOR, José Guilherme. O liberalismo: antigo e moderno. 2. ed. Rio de Janeiro: Nova Fronteira, 1991.

MRE. Ministério das Relações Exteriores. Missão do Brasil junto as Nações Unidas. Discursos. Disponível em: http://delbrasonu.itamaraty.gov.br/pt-br/discursos.xml. Acesso em: 26 jul. 2016.

MOORE JR., Barrington. As Origens Sociais da Ditadura e da Democracia. São Paulo: Martins Fontes, 1983.

MONTESQUIEU, C. L. de S. Baron de La Brède et de. Do espírito das leis. 2. ed. São Paulo: Abril Cultural, 1996.

MOUFFE, C. The Return of the Political. London: Verso, 1997.

O’DONNELL, Guilhermo. Accountability horizontal e novas poliarquias. Lua Nova, 44, 1998.

OEA. Organização dos Estados Americanos. Carta Democrática Interamericana. Disponível em: https://www.oas. org/pt/democratic-charter/pdf/demcharter_pt.pdf. Acesso em: 26 jul. 2016a.

OEA. Organização dos Estados Americanos. Secretário Geral da OEA. Discursos. Disponível em: http://www.oas. org/es/acerca/discurso_secretario_general.asp?sCodigo=16-0031. Acesso em: 26 jul. 2016b.

OEA. Organização dos Estados Americanos. Secretário Geral da OEA. Disponível em: http://www.oas.org/pt/sobre/secretario_geral.asp. Acesso em: 26 jul. 2016c.

RAWLS, J. Justiça como Eqüidade. Uma reformulação. São Paulo: Martins Fontes, 2003.

RAWLS, J. Justiça e democracia. São Paulo: Martins Fontes, 2002.

RAWLS, J. O liberalismo político. 2. ed. São Paulo: Ática, 2000.

RAWLS, J. Uma teoria da justiça. Brasília: Edunb, 1981.

ROUSSEAU, J. J. Discurso sobre a origem e os fundamentos da desigualdade entre os homens. Brasília: Edunb; São Paulo: Ática, 1989.

ROUSSEAU, J. J. Do contrato Social. São Paulo: Nova Cultural, 1997. (Coleção Os Pensadores).

SARTORI, Giovanni. Engenharia constitucional. Como mudam as constituições. Brasília: Edunb, 1996.

SCHUMPETER, J. Capitalismo, socialismo e democracia. Rio de Janeiro: Fundo de Cultura, 1961.

STUART MILL, John. Considerações sobre o governo representativo. Brasília: Edunb, 1981.

TOCQUEVILLE, Aléxis de. A democracia na América. 2. ed. Belo Horizonte: Editora Itatiaia; São Paulo: Editora USP, 1977. (Coleção ler e pensar, 1).

TOURAINE, A. Crítica da modernidade. 5. ed. Petrópolis: Vozes, 1998.

TOURAINE, A. Poderemos viver juntos? Iguais e diferentes. Petrópolis: Vozes, 1999.

TOURAINE, A. O que é a democracia? 2. ed. Petrópolis: Vozes, 1996.

WEBER, M. Economia y Sociedad. Ciudad de México: Fondo de Cultura Económica, 1993.

WEFFORT, Francisco. Qual democracia? São Paulo: Companhia das Letras, 1992. 